\title{
An epidemiological survey of children's iodine nutrition and goitre status in regions with mildly excessive iodine in drinking water in Hebei Province, China
}

\author{
Shengmin $\mathrm{Lv}^{1, *}$, Jun Zhao ${ }^{1}$, Dong $\mathrm{Xu}^{1}$, Zhengshui Chong ${ }^{1}$, Lihui Jia ${ }^{1}$, Yonggui Du ${ }^{1}$, \\ Jing $\mathrm{Ma}^{1}$ and Shannon Rutherford ${ }^{2}$ \\ 'Heibei Provincial Center for Disease Control and Prevention, No. 97, Huai'an East Road, Shijiazhuang \\ 050021, People's Republic of China: ${ }^{2}$ Centre for Environment and Population Health, School of Environment, \\ Griffith University, Brisbane, Australia
}

Submitted 30 August 2011: Accepted 6 January 2012: First published online 8 February 2012

\begin{abstract}
Objective: To identify children's iodine nutrition and goitre status in areas with mildly excessive iodine in drinking water.

Design: A cross-sectional survey. Probability proportional to size sampling was employed to randomly select children from thirty townships where the median iodine content in drinking water ranged from 150 to $300 \mu \mathrm{g} / \mathrm{l}$; their urinary iodine concentrations were determined and their thyroid volumes were measured by ultrasound. Drinking water samples and salt samples from the villages where the children lived were collected using a systematic sampling method.

Setting: Hebei Province of China.

Subjects: A total of 1259 children aged 8-10 years (621 boys and 638 girls).

Results: Children's median urinary iodine concentration was found to be $418 \cdot 8 \mu \mathrm{g} / \mathrm{l}$, and the iodine concentration was $>300 \mu \mathrm{g} / \mathrm{l}$ for $68 \cdot 3 \%$ (248/363) of the urine samples. Children's median urinary iodine concentration in villages with median salt iodine $>10 \mathrm{mg} / \mathrm{kg}$ was significantly higher than that in villages with median salt iodine $<5 \mathrm{mg} / \mathrm{kg}(442 \cdot 9 \mu \mathrm{g} / \mathrm{l} v .305 \cdot 4 \mu \mathrm{g} / \mathrm{l}, P \approx 0)$. The goitre rate of 1259 children examined by ultrasound was $10 \cdot 96 \%$.

Conclusions: The iodine intake of children living in areas with mildly excessive iodine in drinking water in Hebei Province was found to be excessive. The measured iodine excess in the sampled children is exacerbated by consumption of iodized salt. Goitre was identified in these areas; however, due to the limitation of the current criteria for children's thyroid volume, a comprehensive assessment of the prevalence of goitre in these regions could not be made and further study is required.
\end{abstract}

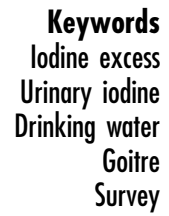

Iodine is an essential trace micronutrient for the human body. Both iodine deficiency and iodine excess can cause thyroid-related health problems. Iodine deficiency has been well studied around the world and is mostly under control in many countries. However, iodine excess and its impacts are still under study. Naturally excessive iodine intake results mainly from consumption of seafood containing a high content of iodine or iodine-rich drinking water. The former has been reported in coastal areas of Japan where seaweed is the staple food of local residents ${ }^{(1,2)}$. The latter is found in some parts of China where the underground drinking water contains a high concentration of iodine, usually $>300 \mu \mathrm{g} / \mathrm{l}^{(3,4)}$. Hebei is one such province in China. According to a survey conducted in Hebei in 2003-2004, thirty-one counties of six prefectures and 173 townships were identified as having excessive iodine (i.e. iodine content $>150 \mu \mathrm{g} / \mathrm{l}$ ) in drinking water based on the National Criteria for Classifying High Iodine Regions $^{(5)}$. This excess iodine potentially affects nearly 6 million people and has became a prominent public health issue now that iodine-deficiency disorders are more successfully managed in Hebei Province ${ }^{(6)}$.

Excessive iodine intake can cause iodine overnutrition, goitre and other thyroid disease ${ }^{(7)}$. Endemic goitre induced by excessive dietary iodine has been reported in coastal areas of Japan where iodine intake from seaweed has been reported as $>10000 \mu \mathrm{g} / \mathrm{d}^{(1,2)}$. In China, a few studies have revealed that excessive iodine in drinking water, mainly from $300 \mu \mathrm{g} / 1$ to $1300 \mu \mathrm{g} / \mathrm{l}$, can cause severe iodine overnutrition and high prevalence of endemic goitre in children aged $8-10$ years $^{(3,4,8)}$. However, the impact of mildly excessive iodine content in drinking water, in the range of $150-300 \mu \mathrm{g} / \mathrm{l}$, on the iodine nutrition and goitre status in children aged 8-10 years remains unclear. 
In the present study, a comprehensive survey of urinary iodine concentration and goitre status in children aged 8-10 years was conducted in thirty townships in Hebei Province of China which had median water iodine between 150 and $300 \mu \mathrm{g} / \mathrm{l}$. The aim of the study was to clarify children's iodine nutrition and goitre status in these areas in order to identify possible harm caused by excessive iodine intake in this vulnerable age group.

\section{Materials and methods}

\section{Sampling method and data collection}

Sample selection (children aged 8-10 years)

Schoolchildren aged 8-10 years are commonly used subjects in surveys on iodine excess owing to their easy access and sensitivity to iodine intake ${ }^{(9)}$. A cluster sampling technique, probability proportional to size sampling, in which the probability that a particular sampling unit will be selected in the sample is proportional to the population size of the sampling unit ${ }^{(10)}$, was employed in the present cross-sectional survey.

With township as the sampling unit, first, thirty townships were selected from 111 townships with median water iodine content between 150 and $300 \mu \mathrm{g} / \mathrm{l}$. One primary school was then randomly selected from each town chosen. Finally forty schoolchildren aged 8-10 years from each school were selected such that a total of 1200 children were selected. Thyroid volume measurement by B-mode ultrasound was conducted for all 1200 children at their schools. Also 360 children from thirty schools (twelve children from each school) were randomly selected for collection of urine samples for measuring urinary iodine concentration. Oral consent for examination of thyroid and urine sample collection was obtained from the headmasters of the investigated schools. The survey was conducted in September of 2009.

\section{Drinking water sample collection}

Drinking water samples were collected from households in the thirty villages where the investigated schoolchildren had lived since birth. The population of each of the thirty villages was between 600 and 2000; twenty-four out of the thirty villages had fewer than five wells, the other six villages had more than five wells. The water samples were collected using a systematic sampling method based on their location. The number of drinking water samples depended on the number of water sources. In a village with more than five wells, five households (one in each of the eastern, western, southern, northern and central parts of the village) covered by these wells were randomly chosen to collect water samples. In a village with fewer than five wells, one household for each well was selected. In a village with a centralized water supply (tap water), one household was randomly selected.

\section{Housebold edible salt sample collection}

Edible salt samples were collected at the villages where the investigated schoolchildren were born and lived. A systematic sampling method was used according to their location of east, west, north, south or centre. Two households were randomly selected in each location to collect edible salt to measure iodine content. A total of ten salt samples were collected in each village.

\section{Measurement of thyroid volume by ultrasound}

Thyroid volume was measured by using an Aloka SSD-500 echocamera (Aloka, Mure, Japan) equipped with $7 \cdot 5-\mathrm{MHz}$ linear transducers. The measurement was performed while the child lay on a bed with his/her neck fully exposed. For each thyroid lobe, the maximum perpendicular anteroposterior and mediolateral dimensions were measured on a transverse image of the largest diameter, without including the isthmus. The maximum craniocaudal diameter of each lobe was then measured on a longitudinal image. The thyroid capsule was not included. The ultrasound measurements were done by one experienced examiner who had specialized in thyroid measurement by ultrasound for 5 years.

Thyroid volume was calculated by using the equation of Brunn et al. ${ }^{(11)}$, in which the volume of each lobe $(\mathrm{ml})$ is equal to anteroposterior diameter $(\mathrm{cm}) \times$ mediolateral diameter $(\mathrm{cm}) \times$ craniocaudal diameter $(\mathrm{cm}) \times 0.479$, and the lobe volumes are summed.

In accordance with the Chinese national criteria for thyroid measurement, goitre was defined by age-specific thyroid volume. The upper limit of thyroid volume for children aged 8,9 and 10 years was $4.5 \mathrm{ml}, 5.0 \mathrm{ml}$ and $6.0 \mathrm{ml}$, respectively. If the child's thyroid volume exceeded the relevant value, the child was judged as goitrous ${ }^{(12)}$.

\section{Data analysis}

\section{Biological sample analysis}

The iodine concentration of urine samples was measured by the method of ammonium persulfate oxidation in the provincial laboratory ${ }^{(13)}$. Urinary iodine concentration values from populations are usually not normally distributed. Therefore, the median rather than the mean should be used as the measure of central tendency. Median urinary iodine concentration of a population is a good biochemical indicator for its iodine nutrition. Median urinary iodine concentration of $300 \mu \mathrm{g} / \mathrm{l}$ and above defines a population as having iodine excess ${ }^{(14)}$.

\section{Environmental sample analysis}

The iodine content of salt was determined quantitatively by titration in the provincial laboratory. Iodine content was measured by liberating iodine from salt and titrating the iodine with sodium thiosulfate using starch as an external indicator ${ }^{(15)}$. According to the Chinese national standard for iodized salt, edible salt with less than $5 \mathrm{mg}$ iodine $/ \mathrm{kg}$ is classified as non-iodized salt. 
The iodine content in drinking water was determined by the method of arsenic-cerium oxidation-reduction spectrophotometry in the provincial laboratory, in which iodine catalyses the oxidation-reduction between arsenious acid and ammonium cerous sulfate ${ }^{(16)}$. It is stipulated in the Chinese national standard for determination and classification of high water and the endemic areas of iodine excess goitre that drinking water containing more than $150 \mu \mathrm{g}$ iodine/l is classified as excessive.

\section{Data processing and statistical analysis}

Data processing and statistical analyses were performed using the statistical software packages Epi-Info ${ }^{\text {TM }} 2002$ (Centers for Disease Control and Prevention, Atlanta, GA, USA) and SPSS version $13 \cdot 0$ (SPSS Inc., Chicago, IL, USA). Since the distributions of iodine in edible salt, drinking water and children's urine are not normal, the median was employed to describe their central tendency. Differences in children's median urinary iodine concentrations by age, sex and different groups classified on the basis of iodized salt were tested with the Mann-Whitney test.

\section{Results}

Iodine content in drinking water and edible salt A total of eighty-five drinking water samples were collected from thirty villages and analysed for iodine content.
The iodine content ranged from $47 \cdot 7 \mu \mathrm{g} / \mathrm{l}$ to $945 \cdot 0 \mu \mathrm{g} / \mathrm{l}$, with the median iodine content being $166 \cdot 0 \mu \mathrm{g} / \mathrm{l}$. Among the thirty villages, the median iodine content in drinking water was $>150 \mu \mathrm{g} / \mathrm{l}$ in twenty villages and $<150 \mu \mathrm{g} / \mathrm{l}$ in ten villages. Water iodine levels in the thirty villages sampled are listed in Table 1 . The number of water samples with iodine content $<150 \mu \mathrm{g} / 1,150-300 \mu \mathrm{g} / \mathrm{l}$ and $>300 \mu \mathrm{g} / \mathrm{l}$ was thirty-four, forty-seven and four, accounting for $40 \cdot 0 \%, 55 \cdot 3 \%$ and $4 \cdot 7 \%$, respectively.

The overall median iodine content of 301 edible salt samples collected at households in the thirty villages was $28.8 \mathrm{mg} / \mathrm{kg}$. In twenty-three villages the median salt iodine was $>10 \mathrm{mg} / \mathrm{kg}$, and in seven villages it was $<5 \mathrm{mg} / \mathrm{kg}$. The details of salt iodine in the thirty villages are listed in Table 1.

\section{Iodine concentration in urine samples of children aged 8-10 years}

A total of 363 urine samples were collected from children aged 8-10 years and analysed for iodine, with the median urinary iodine concentration found to be $418 \cdot 8 \mu \mathrm{g} / \mathrm{l}$. Among the thirty villages investigated, the children's median urinary iodine concentration was $>300 \mu \mathrm{g} / 1$ in twenty-three villages and $<300 \mu \mathrm{g} / \mathrm{l}$ in seven villages.

Of the 363 urine samples, 184 were from boys and 179 from girls. The median urinary iodine concentration in boys and girls was $436.3 \mu \mathrm{g} / \mathrm{l}$ and $398.5 \mu \mathrm{g} / \mathrm{l}$, respectively,

Table 1 The iodine content in edible salt and drinking water at thirty villages investigated in Hebei Province, China, September 2009

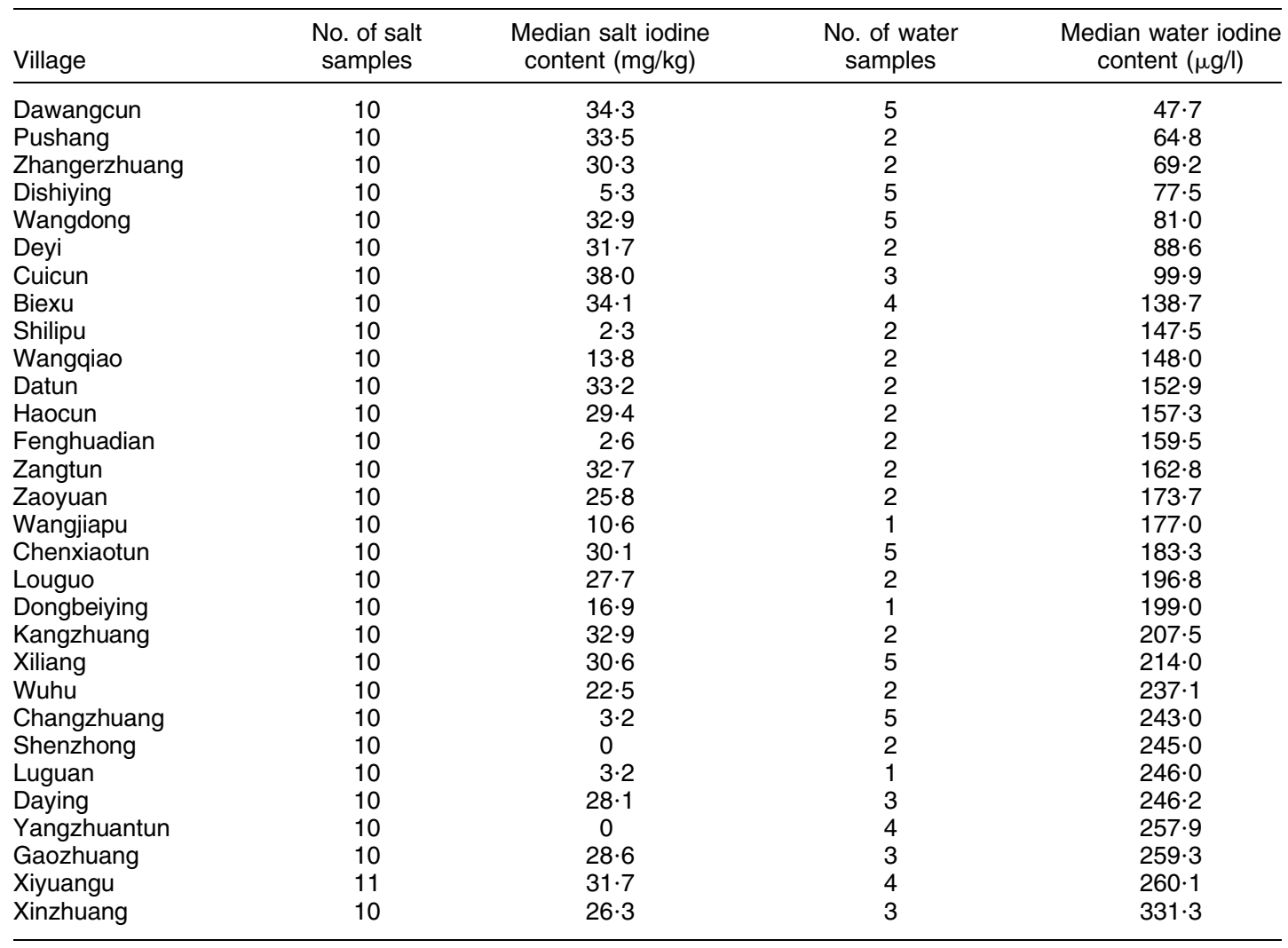


with no statistically significant difference identified (Mann-Whitney $U=15406 \cdot 0, P=0 \cdot 288$ ). The number of urine samples collected from children aged 8, 9 and 10 years was 121, 120 and 122, and their median iodine concentration was $364.3 \mu \mathrm{g} / \mathrm{l}, 425 \cdot 9 \mu \mathrm{g} / \mathrm{l}$ and $441 \cdot 4 \mu \mathrm{g} / \mathrm{l}$, respectively, with no statistically significant difference among them (Mann-Whitney $H=1.563, P=0 \cdot 458$ ).

The iodine concentration was $>300 \mu \mathrm{g} / \mathrm{l}$ in 248 out of 363 urine samples, accounting for $68.3 \%$ in total. In further classification based on age and sex, the percentage of urine samples with iodine concentration $>300 \mu \mathrm{g} / \mathrm{l}$ in each age and sex group varied from $64 \cdot 2 \%$ to $72 \cdot 1 \%$. The median urinary iodine concentration and frequency distribution of urinary iodine concentration of children aged 8-10 years are included in Table 2.

\section{Impact of iodized salt on children's urinary iodine concentration}

Among the twenty villages with median iodine content in drinking water $>150 \mu \mathrm{g} / \mathrm{l}$, the median salt iodine in fifteen villages was $>10 \mathrm{mg} / \mathrm{kg}$. Five villages had salt supplies with median iodine content $<5 \mathrm{mg} / \mathrm{kg}$ or even $0 \mathrm{mg} / \mathrm{kg}$. The median water iodine content in the fifteen villages with high salt iodine and the five villages with low salt iodine was $214 \cdot 0 \mu \mathrm{g} / \mathrm{l}$ and $245 \cdot 7 \mu \mathrm{g} / \mathrm{l}$, respectively, and the difference was not significant $(U=226 \cdot 0, P=0 \cdot 34)$. The median urinary iodine concentration of children aged 8-10 years in the fifteen villages with high salt iodine was $442.9 \mu \mathrm{g} / \mathrm{l}$, while it was $305.4 \mu \mathrm{g} / \mathrm{l}$ in the five villages with low salt iodine, and the difference between them was statistically significant $(U=3810 \cdot 5, P=0)$. Further analysis based on age and sex showed that the median urinary iodine concentrations of children in different age or sex groups in the fifteen villages with high salt iodine were mostly higher than those in the five villages with low salt iodine. In the group of 9-year-olds, the children's median urinary iodine concentration in the fifteen villages with high salt iodine was significantly higher than that in the five villages with low salt iodine, i.e. $457 \cdot 3 \mu \mathrm{g} / \mathrm{l} v \cdot 264 \cdot 3 \mu \mathrm{g} / \mathrm{l}(U=342 \cdot 0, P=0 \cdot 004)$. In the group of 10 -year-olds, it was $497 \cdot 8 \mu \mathrm{g} / \mathrm{l} v .322 .9 \mu \mathrm{g} / 1$ ( $U=4444 \cdot 0, \quad P=0 \cdot 015$ ). Comparing female and male children, it was $440 \cdot 2 \mu \mathrm{g} / \mathrm{l} \quad v .249 \cdot 6 \mu \mathrm{g} / \mathrm{l} \quad(U=843 \cdot 0$, $P=0 \cdot 0)$. Further results of statistical analyses are provided in Table 3.

\section{Goitre status of children aged 8-10 years}

Among the 1259 children aged 8-10 years examined by ultrasound, 138 were found to have goitre, accounting for approximately $11 \%$ of the group. The goitrous cases detected in the 8,9 and 10 year age groups numbered fifty-six, forty-eight and thirty-four, respectively, with the goitre rate being $13 \cdot 1 \%(56 / 426), 11 \cdot 6 \%(48 / 413)$ and $8 \cdot 1 \%(34 / 420)$, respectively. No statistically significant difference was found among the goitre rates across the different age groups $\left(\chi^{2}=5 \cdot 8, P=0 \cdot 06\right)$. In terms of gender, seventy-seven and sixty-one goitrous cases were found in boys and girls, with the goitre rate being $12 \cdot 4 \%(77 / 621)$ and $9 \cdot 6 \%(61 / 638)$. The difference between them was not statistically significant $\left(\chi^{2}=2 \cdot 08\right.$, $P=0 \cdot 15)$. The goitre details by age and sex are included in Table 4 .

Table 2 Median urinary iodine concentrations and distributions for different age and sex groups of children aged 8-10 years, Hebei Province, China, September 2009

\begin{tabular}{|c|c|c|c|c|c|c|c|c|}
\hline \multirow[b]{3}{*}{ Group } & \multirow[b]{3}{*}{ Total no. of samples } & \multicolumn{7}{|c|}{ Urinary iodine concentration } \\
\hline & & \multirow[b]{2}{*}{ Median $(\mu \mathrm{g} / \mathrm{l})$} & \multicolumn{2}{|l|}{$<100 \mu \mathrm{g} / \mathrm{l}$} & \multicolumn{2}{|c|}{$100-300 \mu \mathrm{g} / \mathrm{l}$} & \multicolumn{2}{|l|}{$>300 \mu \mathrm{g} / \mathrm{l}$} \\
\hline & & & No. of samples & $\%$ & No. of samples & $\%$ & No. of samples & $\%$ \\
\hline 8-year-olds & 121 & $364 \cdot 3$ & 5 & $4 \cdot 2$ & 34 & $28 \cdot 0$ & 82 & $67 \cdot 8$ \\
\hline 9-year-olds & 120 & $425 \cdot 9$ & 1 & $0 \cdot 8$ & 42 & $35 \cdot 0$ & 77 & $64 \cdot 2$ \\
\hline 10 -year-olds & 122 & $441 \cdot 4$ & 0 & - & 34 & $27 \cdot 9$ & 88 & $72 \cdot 1$ \\
\hline Boys & 184 & $436 \cdot 3$ & 5 & $2 \cdot 7$ & 52 & $28 \cdot 3$ & 127 & $69 \cdot 0$ \\
\hline Girls & 179 & 398.5 & 1 & $0 \cdot 6$ & 58 & $32 \cdot 4$ & 120 & $67 \cdot 0$ \\
\hline Total & 363 & $418 \cdot 8$ & 6 & $1 \cdot 4$ & 110 & $30 \cdot 3$ & 247 & $68 \cdot 3$ \\
\hline
\end{tabular}

Table 3 Comparison of median urinary iodine concentrations in twenty villages with water iodine content $>150 \mu \mathrm{g} / \mathrm{l}$ according to the presence of iodized salt in the village and for different age and sex groups of children aged 8-10 years, Hebei Province, China, September 2009

\begin{tabular}{|c|c|c|c|c|c|c|}
\hline \multirow[b]{2}{*}{ Group } & \multicolumn{2}{|c|}{ Villages with iodized salt } & \multicolumn{2}{|c|}{ Villages without iodized salt } & \multirow[b]{2}{*}{$U$} & \multirow[b]{2}{*}{$P$} \\
\hline & No. of samples & Median $(\mu \mathrm{g} / \mathrm{l})$ & No. of samples & Median $(\mu \mathrm{g} / \mathrm{l})$ & & \\
\hline 8-year-olds & 62 & $396 \cdot 0$ & 19 & $341 \cdot 6$ & $466 \cdot 0$ & $0 \cdot 17$ \\
\hline 9-year-olds & 60 & $457 \cdot 3$ & 20 & $264 \cdot 3$ & $342 \cdot 0$ & 0.004 \\
\hline 10 -year-olds & 59 & $497 \cdot 8$ & 23 & $322 \cdot 9$ & $4444 \cdot 0$ & 0.015 \\
\hline Boys & 93 & $483 \cdot 0$ & 29 & $322 \cdot 9$ & $1063 \cdot 0$ & 0.086 \\
\hline Girls & 88 & $440 \cdot 2$ & 33 & $249 \cdot 6$ & $843 \cdot 0$ & $\approx 0$ \\
\hline Total & 181 & $442 \cdot 9$ & 62 & $305 \cdot 4$ & $3810 \cdot 5$ & $\approx 0$ \\
\hline
\end{tabular}


Table 4 Comparison of goitre status according to iodine content in drinking water and for different age and sex groups of children aged 8-10 years, Hebei Province, China, September 2009

\begin{tabular}{|c|c|c|c|c|c|c|c|c|c|}
\hline \multirow[b]{2}{*}{ Group } & \multicolumn{3}{|c|}{ Villages with $\mathrm{Wl}<150 \mu \mathrm{g} / \mathrm{l}$} & \multicolumn{3}{|c|}{ Villages with $\mathrm{WI}>150 \mu \mathrm{g} / \mathrm{l}$} & \multicolumn{3}{|c|}{ Total } \\
\hline & No. of children & Goitre cases & $\%$ & No. of children & Goitre cases & $\%$ & No. of children & Goitre cases & $\%$ \\
\hline 8-year-olds & 137 & 17 & $12 \cdot 4$ & 289 & 39 & $13 \cdot 5$ & 426 & 56 & $13 \cdot 1$ \\
\hline 9-year-olds & 140 & 20 & $14 \cdot 3$ & 273 & 28 & $10 \cdot 3$ & 413 & 48 & $11 \cdot 6$ \\
\hline 10 -year-olds & 139 & 8 & $5 \cdot 8$ & 281 & 26 & $9 \cdot 3$ & 420 & 34 & $8 \cdot 1$ \\
\hline Boys & 220 & 25 & $11 \cdot 4$ & 401 & 52 & $13 \cdot 0$ & 621 & 77 & $12 \cdot 4$ \\
\hline Girls & 196 & 20 & $10 \cdot 2$ & 442 & 41 & $9 \cdot 3$ & 638 & 61 & $9 \cdot 6$ \\
\hline Total & 416 & 45 & $10 \cdot 8$ & 843 & 93 & $11 \cdot 0$ & 1259 & 138 & $11 \cdot 0$ \\
\hline
\end{tabular}

WI, water iodine.

The goitre rate in the twenty villages with median iodine content in drinking water $>150 \mu \mathrm{g} / 1$ was $11 \cdot 0 \%$ (93/843), while it was $10 \cdot 8 \%(45 / 416)$ in the ten villages with median iodine content in drinking water $<150 \mu \mathrm{g} / \mathrm{l}$. There was no significant difference between them $\left(\chi^{2}=0 \cdot 01, P=0 \cdot 9\right)$. The goitre comparisons between villages with different water iodine are included in Table 4. The twenty villages with water iodine $>150 \mu \mathrm{g} / \mathrm{l}$ were further broken down into two subgroups based on the status of iodine content in salt. The goitre rate in the group with median salt iodine $>10 \mathrm{mg} / \mathrm{kg}$ was $12 \cdot 1 \%(71 / 587)$ compared with $8 \cdot 6 \%(29 / 339)$ in the group with median salt iodine $<5 \mathrm{mg} / \mathrm{kg}$. However, the difference was not statistically significant $\left(\chi^{2}=2 \cdot 8, P=0 \cdot 094\right)$.

\section{Discussion}

Based on the results of the present survey, the median urinary iodine concentration of children aged 8-10 years in townships in Hebei Province with mildly excessive iodine $(150-300 \mu \mathrm{g} / \mathrm{l})$ in drinking water was $418 \cdot 8 \mu \mathrm{g} / \mathrm{l}$, and $68.3 \%(248 / 363)$ of children's urine samples had iodine concentration $>300 \mu \mathrm{g} / \mathrm{l}$. These results indicate that the iodine intake of local children is excessive. Similar findings were also reported by other researchers in other parts of China with mildly excessive iodine in drinking water. When median water iodine content varied from 90 to $300 \mu \mathrm{g} / \mathrm{l}$, children's median urinary iodine concentration fluctuated from 300 to $800 \mu \mathrm{g} / \mathrm{l}^{(8,17-19)}$.

Children's median urinary iodine concentration found in the present survey was at the lower end of this range. There are two possible reasons for this. One is that the median water iodine in many of the villages investigated was quite low. The median water iodine content in seven villages, accounting for $23.3 \%$ of the total villages investigated, was $<100 \mu \mathrm{g} / \mathrm{l}$, ranging from $47 \cdot 7 \mu \mathrm{g} / 1$ to $99.9 \mu \mathrm{g} / \mathrm{l}$. The other reason is that the supply of iodized salt in some villages, especially those with higher water iodine content, was very poor. The median salt iodine content in six villages was $<5 \mathrm{mg} / \mathrm{kg}$, varying from 0 to $3 \cdot 2 \mathrm{mg} / \mathrm{kg}$, which could provide only $<30 \mu \mathrm{g}$ iodine to the local residents' daily intake, given their average daily salt consumption was estimated to be $10 \mathrm{~g}^{(20)}$ and children's daily salt consumption was even less.
Among the twenty villages with median water iodine $>150 \mu \mathrm{g} / \mathrm{l}$, iodized salt is likely to have played some role in children's iodine excess. Children's urinary iodine concentration in the fifteen villages with median salt iodine $>10 \mathrm{mg} / \mathrm{kg}$ was significantly higher than that in the five villages with median salt iodine $<5 \mathrm{mg} / \mathrm{kg}$, implying that iodized salt increased children's iodine excess.

According to the present survey, the goitre rate of children aged 8-10 years in areas with mildly excessive iodine in drinking water was approximately $11 \%$. This rate is similar to $13 \cdot 1 \%$ in Shanxi Province found by Jia et $a l .{ }^{(21)}$ and $12 \cdot 7 \%$ in Inner Mongolia found by Zhang et $a l^{(22)}$, but is much higher than $5 \%$ reported by Zhao et al. in Jiangsu Province ${ }^{(8)}$, where the median iodine content in drinking water was also in the range of $150-300 \mu \mathrm{g} / 1$ in those investigated areas. There is no doubt that excessive iodine in drinking water can cause goitre in the general population when it is $>300 \mu \mathrm{g} / \mathrm{l}$, and the goitre is more easily detected because of its remarkable enlargement ${ }^{(23,24)}$. However, when the median water iodine content is $<300 \mu \mathrm{g} / \mathrm{l}$, more study needs to be undertaken to determine whether it can cause epidemic goitre in sensitive populations, like young children aged 8-10 years, given the recognized limitations of the criteria on children's normative thyroid volume.

There is still some disagreement on the normative thyroid volume by ultrasound. WHO recommended a set of age-specific normative values for thyroid volume in $1997^{(25)}$, which Zimmerman argued were too high. In 2004, Zimmerman et al. proposed much lower normative thyroid volume values based on samples in iodine-sufficient regions in six countries in Asia, Europe, Africa and America $^{(26)}$. However, they also admitted that populationspecific references for thyroid volume in countries with long-standing iodine sufficiency may be more accurate than a single international reference. Moreover, normative thyroid volume also closely relates with children's age and body surface area, which is due to genetic differences in their growth and development ${ }^{(26)}$.

The normal thyroid volume criteria employed in the present study were formulated in 1996 and were only age-specific. They may be too old and ignore differences in children's development between the present and over 10 years ago in China. Since children's bodies develop 
earlier now than in the 1990s, they may have bigger thyroids than their peers in 1990s and in turn be judged incorrectly as goitrous. The goitre rate obtained in the present study could be amplified by these criteria. Consequently, it is difficult to measure the exact prevailing magnitude of children's goitre with the employed criteria. Therefore, the prevalence of goitre in areas with mildly excessive iodine in drinking water, i.e. 150-300 $\mu \mathrm{g} / 1$, needs to be further researched, in particular identifying more accurate criteria of normal thyroid volume in the future.

The impact of iodine content in the range of $150-300 \mu \mathrm{g} / \mathrm{l}$ in drinking water on the iodine nutrition and goitre status in children aged 8-10 years remains unclear. The present study aimed to clarify to what extent mildly excessive iodine in drinking water influences children's iodine nutrition and goitre status. It revealed that the iodine intake of children living in these areas in Hebei Province was excessive, which was exacerbated by consumption of iodized salt. Goitre was identified in these areas, with children's goitre rate being $10 \cdot 96 \%$. The study adds to Chinese research about dietary iodine exposure. In some parts of China, Chinese public health officials are facing dual challenges relating to both iodine deficiency and iodine excess. These challenges call for good health risk assessment approaches to identify hazardous iodine levels (either too low or too high) in different geographical settings with differing access to iodized salt and differing water iodine levels in order that prevention and control strategies for iodine deficiency or iodine excess can better be designed to meet the needs of each geographic area.

\section{Acknowledgements}

This research did not receive any specific grant from any funding agency in the public, commercial or not-for-profit sector. The authors declare no conflict of interest. S.L. was responsible for the study design, data analysis, paper writing and field investigation. J.Z. was in charge of the laboratory detection of iodine. D.X. did the thyroid measurements by ultrasound. S.R. was responsible for the paper revision and English polishing. Z.C., L.J., Y.D. and J.M. took part in the field investigation.

\section{References}

1. Suzuki H, Higuchi T, Sawa K et al. (1965) 'Endemic coast goiter' in Hokkaido, Japan. Acta Endocrinol 50, 161-176.

2. Katamine S, Mamiya Y, Sekimoto K et al. (1986) Iodine content of various meals currently consumed by urban Japanese. J Nutr Sci Vitaminol 32, 487-495.

3. Li M, Liu D, Qu C et al. (1987) Endemic goiter in Central China caused by excessive iodine intake. Lancet $2,257-259$.

4. Zhao I, Chen Z \& Maberly G (1998) Iodine-rich drinking water of natural origin in China. Lancet 352, 2024-2025.

5. Ma DR, Zhou RH, Jia LH et al. (2006) Survey on the distribution of the areas with excessive iodine in drinking water in Hebei plain. Chin J Endem Dis 21, 237-238 (in Chinese).

6. Lv SM, Xie LJ, Zhou RH et al. (2009) Control of iodine deficiency disorders following 10-year universal salt iodization in Hebei province of China. Biomed Environ Sci 22, 472-479.

7. Hans B (2010) Iodine excess. Best Pract Res Clin Endocinol Metab 24, 107-115.

8. Zhao JK, Wang PH, Shang L et al. (2000) Endemic goiter associated with high iodine intake. Am J Public Health 90, $1633-1635$.

9. Yv ZH, Zhu HM, Chen CY et al. (1999) Proceedings of the study on endemic goiter caused by iodine excess. Chin J Endemiol 18, 301-304 (in Chinese).

10. World Health Organization/UNICEF/International Council for Control of Iodine Deficiency Disorders (2008) Elimination of Iodine Deficiency Disorders: A Manual for Health Workers. Cairo: WHO Regional Office for the Eastern Mediterranean.

11. Brunn J, Block U, Ruf G et al. (1981) Volumetric analysis of thyroid lobes by real-time ultrasound. Dtsch Med Wochenschr 106, 1338-1340 (in German).

12. Ministry of Health (2007) Diagnostic Criterion for Endemic Goiter. Beijing: $\mathrm{MOH}$ (in Chinese).

13. Ministry of Health (2006) Method for Determination of Iodine in Urine by $\mathrm{As}^{3+}-\mathrm{Ce}^{4+}$ Catalytic Spectrophotometry. Beijing: $\mathrm{MOH}$ (in Chinese).

14. World Health Organization (1994) Indicators for Assessing Iodine Deficiency Disorders and their Control through Salt Iodization. Geneva: WHO/UNICEF/ICCIDD.

15. State Bureau of Quality and Technical Supervision (1999) General Test Method in Salt Industry - Determination of Iodide Ion. Beijing: SBQTS (in Chinese).

16. Ministry of Health (2006) The Standard Test Method for Drinking Water. Beijing: $\mathrm{MOH}$.

17. Guo XW, Qin QL \& Chen ZP (2007) Iodine nutrition status of population in the areas with different iodine concentrations of drinking water. Acta Nutrimenta Sinica 29, 526-534 (in Chinese).

18. Zhang XD, Jia QZ, Wang ZH et al. (2007) Epidemiological survey of inland water-borne high iodine in drinking water in Shanxi Province. Chin Trop Med 17, 679-681 (in Chinese).

19. Guo XW, Qin QL, Liu CJ et al. (2007) Study on iodine nutritional status of target population due to different iodine concentrations in drinking water after stopped iodized salt. J Hyg Res 36, 427-431 (in Chinese).

20. Xu TC, Wang ZF, Hu P et al. (2009) Existing problems and their solutions of diet structure in China. Food Nutr Chin $\mathbf{4}$, 57-59.

21. Jia QZ, Zhang XD, Wang ZH et al. (2006) An epidemiological study on the distributive characters and the harm of high water iodine in Shanxi Province. Chin J Endemiol 25, 294-296 (in Chinese).

22. Zhang ZZ, Fan J, Guo HY et al. (2007) Distribution and goiter status of areas with high iodine in Inner Mongolia. J Baotou Med Col 23, 466-468 (in Chinese).

23. Zimmermann MB, Ito Y, Hess SY et al. (2005) High thyroid volume in children with excess dietary iodine intakes. $\mathrm{Am} \mathrm{J}$ Clin Nutr 81, 840-844.

24. Yu ZH, Chen CY \& Tan FZ (2001) Identification process and distribution profile of endemic goiter induced by high iodine in China. Chin J Prev Med 35, 351-352 (in Chinese).

25. World Health Organization/International Council for Control of Iodine Deficiency Disorders (1997) Recommended normative values for thyroid volume in children aged 6-15y. Bull World Health Organ 75, 95-97.

26. Zimmermann MB, Hess SY, Molinari L et al. (2004) New reference values for thyroid volume by ultrasound in iodinesufficient schoolchildren: a World Health Organization/ Nutrition for Health and Development Iodine Deficiency Study Group Report. Am J Clin Nutr 79, 231-237. 